\title{
Misplaced Intrauterine Contraceptive Device (IUCD) Presentation, Diagnosis and Management
}

\author{
Farhana Shaikh, Naheed Parveen, Agha Taj Mohammad
}

\begin{abstract}
OBJECTIVE: To determine the Presentation, Diagnosis and Management of Misplaced Intrauterine Contraceptive Device (IUCD).

METHEDOLOGY: It was an observational retrospective study carried out in the obstetrics and gynecology Unit II, Liaquat University of Medical and Health Sciences Jamshoro from January 2016 to December 2017. Twenty patients enrolled were presented / referred with missing IUCD thread or misplaced IUCD . Performa was designed which contained age, parity, whom inserted, place and duration of IUCD insertion and clinical presentation. Other parameters of Performa contained diagnostic tools for localization of IUCD, and procedure for retrieval of IUCD.

RESULTS: During study period 391 patients were gynae admissions out of them 20 had misplaced IUCD so frequency of misplaced IUCD was $5.11 \%$. 13(65\%) patients were grand multipara, $12(60 \%)$ were $26-40$ years of age, $11(55 \%)$ of women presented with complain of loss string of IUCD, lower abdominal pain in $3(15 \%)$, menstrual problem in $5(25 \%)$, and pregnancy with IUCD in $1(5 \%)$. In $8(40 \%)$ women IUCD was removed with curettage and retrieval forceps, $5(25 \%)$ of patients IUCD was removed directly from cervical canal. In $7(35 \%)$ laparotomy was performed for IUCD removal.

CONCLUSION: IUCD is mostly inserted by lady health workers and family planning staff without prior assessment and training. Therefore proper training program should be arrange for community health care professionals to provide better, safe and effective family planning services for community and reduce the occurance of misplaced IUCD or perforation of uterus and it sequel.
\end{abstract}

KEYWORDS: Misplaced intrauterine contaceptive device, Lost string, Retrieval hook, Laparotomy.

This article may be cited as: Shaikh F, Parveen N, Mohammad AT. Misplaced Intrauterine Contraceptive Device (IUCD) Presentation, Diagnosis and Management. J Liaquat Uni Med Health Sci. 2019;18(04):272-5. doi: 10.22442/jlumhs.191840641

\section{INTRODUCTION}

Intrauterine Contraceptive Device (IUCD) is most common, reversible method of contraception widely used among married women of reproductive age. World wide 128 millions of women have IUCD ${ }^{1}$ as method of choice for contraception. Copper releasing IUCD are commonly used. They are highly effective method with failure rate of less than $1 / 1000$ women per year and IUCDS may be misplaced in as many in $5 \%$ of cases ${ }^{2}$.

IUCD are considered as safe cheap and effective method of contraception. It has no effect on sexual activity and is also acceptable by lactating mother because it has no effect on breast milk quality and composition $^{3}$ and not interfere with breast feeding, although it is not acceptable by some women because of its side effects and complications such as menorrhagia, dysmenorrhea, pain, infection, expulsion and perforation of uterine wall.

It is commonly inserted by paramedical staff, lady health worker, family planning clinic, so inadequate pelvic assessment prior to insertion and inexperience person result in misplaced IUCD or perforation of uterus and its sequel ${ }^{4}$.

Once inserted its presence is monitored by feeling of string of device. On monitoring when if string is not felt possibilities includes expulsion of device, curling of thread into cervical canal, broken thread, withdrawal of device into uterus, uterine perforation and translocation of IUCD ${ }^{5}$. Rarely IUCD was presented with pregnancy and some women remain asymptomatic for longer time ${ }^{6}$.

Localization of IUCD in situ could be confirmed by careful speculum examination. Ultrasound examination, x-ray and sometimes with non contrast computed tomography $(\mathrm{NCCT})^{7}$ of pelvis and abdomen.

When IUCD is in peritoneal cavity, results increase risk of adhesion formation and damage to the surrounding viscera such as intestine and urinary bladder $^{8}$, so it should be removed by laparotomy. Depending upon its location and facilities available retrieval of IUCD needs uterine exploration with hysteroscope, D\&C, laparoscopy or laparotomy

\section{METHODOLOGY}

This observational retrospective study was conducted 
in Department of Obstetrics \& Gynaecology Unit II, Liaquat University of Medical and Health Sciences Jamshoro from January 2016 to December 2017. Data was collected from hospital records so departmental approval was obtained. Inclusion criteria were all women whose IUCD string could not be visualized on examination at the external cervical os but Ultrasound and X-Rays findings confirms its presence.

Exclusion criteria includes the women in whom there is no Ultrasound or X-Ray evidence of IUCD. All patients were presented or referred with history of lost string of device or misplaced IUCD were enrolled in this study. Performa was designed contain information regarding patients age, parity, when and where IUCD was inserted, duration of its insertion, presentation or complaints, Ultrasound findings, location and mode of IUCD retrieval. All the statistical analysis were performed by using SPSS version 16 .

\section{RESULTS}

Total 2412 patients were admitted in Gynae Unit II, Liaquat University of Medical and Health Sciences during study period, amongst them 391 were Gynae patients and 20 patients had displaced IUCD. Twelve $12(60 \%)$ of women belonged to the age group of $26-40$ years and $13(65 \%)$ were multiparous (Table I).

Among 20 women, $55 \%$ had lost string of IUCD, lower abdominal pain in $15 \%$, heavy and irregular menses in $25 \%$ and $5 \%$ of them presented with pregnancy with IUCD (Table III).

Out of 20 women, $25 \%$ of women IUCD was found in cervical canal and was removed directly with retrieval forceps, in $40 \%$ of women IUCD was found in uterus and removed after dilatation and curettage. In $35 \%$ of patient IUCD was found in peritoneal cavity so laparotomy was performed (Table III).

IUCD were copper-T in all cases. Seven (7) copper IUCD were inserted by lady health visitors, 5 by dais (midwifes), 5 by doctor and 3 in family planning centre.

TABLE I: AGE AND PARITY OF PATIENTS

\begin{tabular}{|c|c|c|}
\hline & $\begin{array}{c}\text { Number of } \\
\text { patients }(\mathbf{n = 2 0})\end{array}$ & Percentage (\%) \\
\hline Age (Years) & & \\
\hline $20-25$ & 03 & 15 \\
\hline $26-40$ & 12 & 60 \\
\hline$>40$ & 05 & 25 \\
\hline Parity & & \\
\hline $1-3$ & 04 & 20 \\
\hline $4-6$ & 13 & 65 \\
\hline$>6$ & 03 & 15 \\
\hline
\end{tabular}

TABLE II: CLINICAL PRESENTATION

\begin{tabular}{|l|c|c|}
\hline \multicolumn{1}{|c|}{ Symptoms } & No of women & Percentage \\
\hline Lost string of IUCD & 11 & 55 \\
\hline Abdominal pain & 03 & 15 \\
\hline $\begin{array}{l}\text { Menstrual abnormality } \\
\text { (Heavy or irregular } \\
\text { vaginal bleeding) }\end{array}$ & 05 & 25 \\
\hline Pregnancy with IUCD & 01 & 05 \\
\hline
\end{tabular}

TABLE III: PROCEDURE PERFORMED

\begin{tabular}{|l|l|c|c|}
\hline \multicolumn{1}{|c|}{$\begin{array}{c}\text { Surgical } \\
\text { Procedure }\end{array}$} & Location & $\begin{array}{c}\text { Number } \\
\text { of women }\end{array}$ & Percentage \\
\hline $\begin{array}{l}\text { Cervical } \\
\text { dilatation and } \\
\text { removal of IUCD }\end{array}$ & Cervical canal & 05 & 25 \\
\hline $\begin{array}{l}\text { Dilatation and } \\
\text { uterine cavity } \\
\text { exploration with } \\
\text { curette or } \\
\text { retrieval hook }\end{array}$ & Uterus & 08 & 40 \\
\hline & $\begin{array}{l}\text { IUCD adherent } \\
\text { to omentum /gut }\end{array}$ & 05 & 25 \\
\cline { 2 - 5 } & $\begin{array}{l}\text { IUCD from tubo } \\
\text { ovarian mass }\end{array}$ & 01 & 05 \\
\cline { 2 - 5 } & $\begin{array}{l}\text { IUCD in pouch } \\
\text { of douglas }\end{array}$ & 01 & 05 \\
\hline
\end{tabular}

\section{DISCUSSION}

IUCD is reversible cheap and easily available and effective method of contraception. Commonly used IUCD are copper T or multiload. It is inserted in postmenstrual period or after abortion or immediately after delivery or in puerperium. Despite its cost effective and reliability it is non accepted by most of women because of its complications such as menorrhagia, pain, infection and perforation of uterus.

Presence of IUCD in situ is monitored by checking its string by women herself or by health care provider. Lost string means IUCD in situ with curling up of string in cervical canal, or expulsion or perforation of uterus ${ }^{4}$ and migration to adjacent organs. Rare possibilities includes; fragmentation of IUCD with expulsion of the fragment containing the string or migration of IUCD into the uterotubal junction ${ }^{9}$.

In our study $55 \%$ of women were presented with lost string of IUCD. In Jillani K $2010^{10}$ and Gupta N 2014 study presentation of lost string were found in $40.90 \%$ and $37.83 \%$ respectively.

Twenty five percent of women in our study were presented with menstrual abnormality commonly menorrhagia, while in Jillani K $2010^{10}$ and Gupta N 
$2014^{4}$ studies it was $9.90 \%$ and $24.32 \%$ respectively. Pain in abdomen was found in $15 \%$ of women. Its main presentation in study by Elahi $\mathrm{N} 2002^{11}$ was $42.86 \%$.

In our study $5 \%$ of woman were presented with pregnancy at 9 weeks of gestation with device in cervical canal so device was removed easily without any complication. In Jillani $\mathrm{K} 2010^{10}$ and Ellahi $\mathrm{N}$ $2002^{11}$ studies it was $9.90 \%$ and $7.71 \%$ respectively.

In $8(40 \%)$ of patient IUCD was in uterine cavity and its removal needed D\&C and was removed with retrieval hook. According to Jillani K $2010^{10}$ and Barsaul M $2003^{12}$ and Lawal SO $1993^{13}$ device was inside the uterine cavity in $54.54 \%, 79.79 \%, 63.48 \%$ patients respectively.

In our study $5(25 \%)$ of patient IUCD was in cervical canal which was removed after dilatation of cervix.

In our study $7(35 \%)$ of patient there was complete uterine perforation and migration of device into peritoneal cavity and laparotomy was performed, out of 7 women $5(25 \%)$ of patient device were adherent to gut and omentum and was removed. In $1(5 \%)$ of patient IUCD from tubo ovarian mass was removed. In $1(5 \%)$ patient found in pouch of douglas. In Jillani $\mathrm{K}$ $2010^{10}$ \& Ellahi N $2002^{11}$ migration to peritoneal cavity was found in $40.90 \%$ and $28.5 \%$ respectively. In contrast to our study some unusual cases seen in which IUCD was found in bladder, partially embedded in fallopian tube and found near iliac region embedded in abdominal wall adherent to omentum respectively $8,14,15$.

Removal of IUCD is not always easy it needs laparotomy if perforate uterus and found in abdominal cavity after as in our study but if facility and expertise is available its better to visualize, locate and remove it by laparoscopically as carried out in Varun N $2017^{16}$ study.

\section{CONCLUSION}

To provide better safe and effective family planning services for community and to reduce the complication such as misplaced IUCD and perforation of uterus and its sequele proper training program should be arranged for community health professionals because most of the time IUCD is inserted by lady health workers and family planning staff without proper assessment.

Ethical permission: Ref. No. LUMHS/ CHAIRPERSON.OBGYN/040-19. Dated: 28-06-2019

Conflict of interest: Authors of the study have no conflict of interest to declare.
Funding: There was no any funding agency.

\section{REFERENCES}

1. Verma U, Gupta M, Saini V. Missing IUCD string: an analysis. Int J Reprod Contracept Obstet Gynecol. 2018; 7(10): 4061-67. doi:10.18203/23201770.ijrcog20184129

2. Gupta M, Jain G. Misplaced IUCD: Challenges and Management. Peoples J Sci Res. 2016; 9(2): 14-17.

3. Bhalerao AR, Purandare MC. Post-puerperal Cu-T insertion: A prospective study. J Postgrad Med. 1989; 35(2): 70-3.

4. Gupta N, Gupta T, Gupta S, Jain J, Wahi S. Misplaced IUCD Incidence, Presentation and Complication. J Univ Coll Med Sci. 2014; 2(1): 2023. doi: 10.3126/jucms.v2i1.10486.

5. Al-Inany $\mathrm{H}$. Current state of intrauterine contraceptive devices. Middle East Fertil Soc J. 2007; 12 (01): 8-12.

6. Kim SK, Romero R, Kusanovic JP, Erez O, Vaisbuch E, Mazaki-Tovi S, et al. Prognosis of pregnancy conceived despite presence of intrauterine device. J Perinat Med. 2010; 38(1): 45-53. doi: 10.1515/JPM.2009.133.

7. Goswami D, Ravi AK, Sharma A. Missing IUCD strings: Role of Imaging in Locating the Misplaced Device. J Clin Diagn Res. 2017; 11(4): QJ01QJ02. doi: 10.7860/JCDR/2017/24659. 9757.

8. Markovitch $\mathrm{O}$, Klein Z, Gidoni $\mathrm{Y}$, Holzinger $\mathrm{M}$, Beyth Y. Extrauterine mislocated IUD: Is surgical removal mandatory? Contraception. 2002; 66 (2): 105-8.

9. Guillebaud J. Scheme for management of lost IUD threads. IPPF Med Bull. 1980; 14(5): 1-3.

10. Jillani K, Khero RB, Maqsood S. Diagnosis and Management of Misplaced Intrauterine Contraceptive Device (IUCD). Pak J Surg. 2010; 26(2): 151-54.

11. Elahi N, Koukab H. Diagnosis and Management of Lost Intrauterine Contraceptive Device. J Pak Med Assoc. 2002; 52(1): 18-20.

12. Barsaul M, Sharma N, Sangwan K. 324 cases of misplaced IUCD- a 5-year study. Trop Doct. 2003; 33(1): 11-12.

13. Lawal SO, Giwa-Osagie OF, Ogedengbe OK, Usifoh C. A review of referred IUCD related problems in Lagos University Teaching Hospital. West Afr J Med. 1993; 12(3): 144-7.

14. Goldbach AR, Hava S, Patel H, Khan M. IUD embedment in the fallopian tube an unexpected location for translocated IUD. Radiol Case Rep. 
2018; 13(4): 788-92. doi: 10.1016/j.radcr.2018. 04.030 .

15. Raj AD, Singh MK, Soma MM. Misplaced IUCD: a case report. Int J Reprod Contracept Obstet Gynecol. 2018; 7(7): 2979-81. doi:10.18203/2320- 1770.ijrcog20182922.

16. Varun N, Nigam A, Gupta N. Misplaced IUCD: a case report. Int J Reprod Contracept Obstet Gynecol. 2017; 6(11): 5155-57. doi:10.18203/2320-1770.ijrcog20175044.

AUTHOR AFFILIATION:
Dr. Farhana Shaikh (Corresponding Author)
Associate Professor
Department of Obst and Gynae
Liaquat University of Medical \& Health Sciences
(LUMHS), Jamshoro, Sindh-Pakistan.
Email: farhanashaikh_328@yahoo.com
Dr. Naheed Parveen
Associate Professor
Department of Obst and Gynae
LUMHS, Jamshoro, Sindh-Pakistan.
Dr. Agha Taj Mohammad
Associate Professor
Department of Surgery
LUMHS, Jamshoro, Sindh-Pakistan.

